Commentary

\title{
EU Transparency as 'Documents': Still Fit for Purpose?
}

\author{
Maarten Hillebrandt
}

Eric Castrén Institute, Faculty of Law, University of Helsinki, 00101 Helsinki, Finland; E-Mail: maarten.hillebrandt@helsinki.fi

Submitted: 2 February 2021 | Accepted: 12 February 2021 | Published: 31 March 2021

\begin{abstract}
In this thematic issue, the question whether EU decision making might be characterised by an excess of transparency stands central. This contribution addresses an issue that precedes such questions of quantity: that of transparency's qualities, i.e., its specific shape. From an early point in time, transparency in the EU has been equated with the narrow and legalistic notion of 'access to documents.' Although since then, transparency has become associated with a wider range of practices, the Union has not managed to shake off the concept's association with bureaucracy, opacity, and complexity. This remains the case, in spite of the fact that administrations and decision-makers across the world increasingly utilise the possibilities of technological innovation to communicate more directly with their electorates. In this changing communicative context, this commentary considers whether EU transparency as access to documents is still fit for purpose. It does so by exploring access policy from the vantage point of legal developments, administrative practices, political dynamics, and technological innovations. The commentary concludes that while improvements are needed, the access to documents concept endures. However, access to documents needs to be complemented by constructive (rather than predatory) public justification and contestation, to remain viable.
\end{abstract}

\section{Keywords}

access to documents; administrative circumvention; document base; European Union; record keeping; transparency

\section{Issue}

This commentary is part of the issue "Access or Excess? Redefining the Boundaries of Transparency in the EU's DecisionMaking" edited by Camille Kelbel (Lille Catholic University, France), Axel Marx (University of Leuven, Belgium) and Julien Navarro (Lille Catholic University, France).

(C) 2021 by the author; licensee Cogitatio (Lisbon, Portugal). This commentary is licensed under a Creative Commons Attribution 4.0 International License (CC BY).

\section{Introduction}

Government transparency is a many-faced metaphor. Ask 10 citizens (or, for that matter, politicians) how they think government should be made more transparent, and you might expect eleven answers. In the EU context however, the notion of transparency was quickly boxed in. As soon as clamours for a more transparent EU emerged in the early 1990s, the Council and Commission, soon followed by the Parliament, agreed to cast transparency in the mould of access to documents (Council \& Commission Code of Conduct of 31 December 1993, 1993); European Parliament Decision of 10 July 1997, 1997). This put the Union on a clear institutional path, culminating in a treaty base and dedicated legislation in the form of Regulation 1049/2001 (2001) on access to the institutions' documents.
To be true, other important transparency provisions, most notably related to open legislative meetings and lobbying, followed suit, most recently, with the adoption of an interinstitutional agreement on a lobby register. Nevertheless, access to documents remains the unmistakable frontispiece of the Union's transparency efforts. Under the legal letter of Regulation 1049/2001, "applicants" request documents "held by an institution," subject to exceptions determined within a carefully calibrated application procedure and overseen by the Court of Justice and the Ombudsman. EU transparency thus unmistakably functions foremost "in the humdrum world of administrative laws," experts, and courts (Fenster, 2015, p. 150; see also Hood, 2007, pp. 195-196). As a result, the Union is still perceived as complex and thus opaque. 
The neigh-automatic association of 'transparency' with 'documents' in the EU may largely be explained by its ready availability and acceptability as a policy template at the time of adoption. However, it is less obvious in light of the ambitious normative substance it sought to carry. According to political declarations of the time, transparency was supposed to explain the EU better, bring it closer to citizens, and enable them to participate more actively in decision-making processes. In a context where decision-makers and citizens connect directly through new technologies, the question seems warranted whether the EU's strong reliance on transparency as access to documents still fits the bill. This contribution explores this question from the perspective of respectively the law, administrative and political practices, and technological innovations in the EU.

\section{EU Access to Documents in a Changing Context}

From the outset, the approach to access to documents policy has been decisively legalistic. Initially, this was used as a defence mechanism to keep curious journalists out of the door. Over time, it resulted in a greater role for the Court of Justice, which often expanded the interpretation of the access rules. However, the policy's legalistic approach also alienated all but the most dogged EU citizens, or those that possess the requisite legal knowledge or have the financial resources to acquire it. The right of access to documents has been characterised as 'wide but shallow': It covers many forms of information and most entities and instances, but is hard to enforce in a manner that preserves its utility. Courts, for example, cannot apply coercive instruments, such as fines, to compel institutions to comply (Rossi \& Vinagre e Silva, 2017). What is more, certain important functional aspects of the decision-making process remain out of the remit of the rules. Importantly, the right of access only applies to documents that already exist. A few limited exceptions aside (such as the duty to publish voting outcomes), institutions are not bound to minimal record-keeping standards. Moreover, lobby inputs directed towards the Union legislator are equally not covered by the access rules.

The above-described legal circumstances spill over into the administrative realm. What immediately strikes access requesters is the formalism of the procedure, larded with references to legal doctrine, often to signal limitations in the institutions' access obligations. Applicants may easily experience such formalism as attempts to thwart their access rights. When considering the material aspect of disclosure practices, we see that the online 'interface' for accessing documents creates various hurdles. Dispersed across multiple registers, the institutions' hundreds of thousands of documents can only be retrieved via search forms containing largely imponderable 'legalese' search categories. Open search criteria such as 'word in title' in turn yield document inventories of which only policy experts are in a position to guesstimate the completeness or coherence. One level deeper, the potential of documents as vessels of transparency depends on their quality. In a classical view of the bureaucratic organisation, this should be a good fit, as efficient decision-making requires sound recordkeeping for tracking progress, stabilising calibrated compromises, and preserving institutional memory. In reality, document management suffers from inconsistent drafting and registration practices, exclusion of important information from records, and key documents occasionally getting lost (European Court of Auditors, 2016, paras. 71-75; Hillebrandt \& Novak, 2016, p. 533).

The latter point chimes with the political perspective of access to documents in the EU. Political decisionmakers prefer informal decision-making, as manifested by consensus-oriented negotiating norms in both internal and interinstitutional negotiations. Particularly in the Council, characterised by lingering diplomatic norms, publicity of political differences is not considered in the institution's best interest (Andrzejewski, 2020). In this context, implementing public access to documents is like asking the fox the guard the henhouse. Although transparency suppression is subject to court oversight, circumvention methods are manifold and difficult to police. Controversial documents, for example, are routinely disclosed with a large time lag, to allow member states to negotiate compromises before the public is informed (Cross \& Bølstad, 2015, p. 219). The fact that the EU decision-making system is hard-wired for consensusoriented informality means that decision-makers take measures to control the flow and timing of information disclosures, with the purpose of claiming successes and disowning failures. In extreme situations, this leads to leaks or hostile press releases aiming to derail negotiations or paint the EU in a bad light (Bayer, 2019). In such cases, disclosure replaces the bureaucratic logic of access to documents as 'objective reporting' with a political logic of obstruction and virtue signalling.

Finally, access to documents can be considered from a technological perspective. In a tangible way, the establishment of online registers amplified access to documents policy compared to pre-Internet days, by reducing the transaction costs of accessing EU documents. In the Council, for example, access applications initially quadrupled and eventually multiplied nine-fold compared to access request directly before implementation of the register. The number of visitors consulting documents directly online is well over a hundred times larger. Digital formats such as data- and meta-datasets further enrich the legal concept of a 'document.' However, another new incarnation, that of digital and portable communication tools, poses more of a problem for access rights. As significant parts of negotiations move to email and apps, essential information risks being excluded from the right of public access (e. g. European Council, 2019). More recent still is the increased role of political communication through social media. Phenomena such as 'Wikileaks world' (Hood, 2011) or 'Trumping transparency' (Birchall, 2018), have not gained ground in the 
EU context to the extent seen in the US. Still, social media have gained a toehold when it comes to system-hostile communication, relying on false or deliberately misrepresented information from official sources (particularly certain member state governments). Such political messaging does not fit well within the bureaucratic model of transparency manifest in access to documents policy.

\section{Conclusion}

Is EU access to documents (still) fit for purpose as a vehicle for transparency? This commentary answers with a cautious and qualified 'yes.' In spite of the various shortcomings highlighted, access to documents in its broad outline remains capable of fulfilling transparency requirements. The definition of a document under EU law is broad enough to capture its latest manifestations unknown at the time of the adoption of Regulation 1049/2001. Moreover, the EU's organisational nature should correspond well to the bureaucratic medium of documents. And while administrations' sprawling nature makes transparency "improbable" in any government context (Fenster, 2015, pp. 161-162), adequate implementation interfaces may go a considerable way in taming complex information, by tying it to manageable cognitive categories such as procedure, chronology, and actors' formal roles. Early technological advances demonstrate that major improvement in unlocking complex information in Internet-based infrastructures is possible. Three decades after its introduction, the essential features of access to documents policy thus remain upright.

This positive assessment however is bracketed by two pivotal observations. First, the formalism and legalism that underpin access to documents policy severely restrict its reach. In practice 'EU transparency is not where the people are.' This debilitating condition is intensified by political norms of consensus-oriented informality, leading EU institutions to develop administrative methods that limit, slow down, or evade document-based transparency. Both the law in place and available technologies are in themselves agnostic instruments that can be used to unveil and to conceal. Shortcomings in the access to documents concept thus lie foremost within the administrative and political sphere, where it is sometimes considered an alltoo-intrusive means for demonstrating one's commitment to transparency, and selective communication is thus preferred.

Second, in order to remain viable, the fact-based 'process orientation' of access to documents requires non-document-based complementary communication with a 'rationale orientation.' Public political justification and contestation contextualises official information and brings it to life (Mansbridge, 2009). Mass and social media are well positioned for such communication, being considerably faster, more readily accessible, and less complex in content than access to documents pol- icy. However, in the absence of constructive justification and contestation, predatory political messaging is given the opportunity to fill the vacuum and challenge systemlegitimating notions of transparency. Thus, as long as citizens give their European leaders carte blanche to engage in 'access to documents as usual,' particularly the technocrats and populists among them stand to gain.

\section{Acknowledgments}

This publication appears in the context of the Academy of Finland-funded project 'Transparency in the EU: from Reaction to Manifesto?' whose funding the author gratefully acknowledges. The author would further like to thank the Academic Editors of this thematic issue for their support, the participants of the RECONNECT conference "Transparency in the EU: mechanisms and practices," held in Lille on 19-20 November 2019 for fruitful exchanges on the subject, and Marlen Heide for insightful comments on an earlier version of this draft.

\section{Conflict of Interests}

The author declares no conflict of interests.

\section{References}

Andrzejewski, C. (2020, December 8). Interview with Pierre Sellal, France's former permanent representative to the EU. Investigate Europe. Retrieved from https://www.investigate-europe.eu/en/2020/ pierre-sellal

Bayer, L. (2019, December 10). Hungary clashes with other EU members in rule-of-law hearing. Politico. Retrieved from https://www.politico.eu/article/ hungary-clashes-with-eu-governments-in-rule-oflaw-hearing

Birchall, C. (2018). Interrupting transparency. In E. Alloa \& D. Thomä (Eds.), Transparency, society, and subjectivity: Critical perspectives (pp. 343-367). London: Palgrave Macmillan.

Council \& Commission Code of Conduct No 93/730/EC of 31 December 1993 concerning public access to Council and Commission documents. (1993). Official Journal of the European Union, L340/41.

Cross, J. P., \& Bølstad, J. (2015). Openness and censorship in the European Union: An interrupted time series analysis. European Union Politics, 16(2), 216-240.

European Council. (2019). Confirmatory application No. 09/c/01/19, 15 May 2019. Unpublished document.

European Court of Auditors. (2016). Financial assistance provided to countries in difficulties, 26 January 2016 (Special Report No. 18/2015). Luxembourg: Publications Office of the European Union.

European Parliament Decision (EC) No 97/632/ESCS, Euratom of 10 July 1997 on public access to European 
Parliament documents. (1997). Official Journal of the European Union, L263/27.

Fenster, M. (2015). Transparency in search of a theory. European Journal of Social Theory, 18(2), 150-167.

Hillebrandt, M., \& Novak, S. (2016). 'Integration without transparency'? Reliance on the space to think in the European Council and Council. Journal of European Integration, 38(5), 527-540.

Hood, C. (2007). What happens when transparency meets blame avoidance? Public Management Review 9(2), 191-210.

Hood, C. (2011). From FOI world to Wikileaks world. Gov- ernance, 24(4), 635-638.

Mansbridge, J. (2009). A 'selection model' of political representation. Journal of Political Philosophy, 17(4), 369-398.

Regulation (EC) No 1049/2001 of the European Parliament and of the Council of 30 May 2001 regarding public access to European Parliament, Council and Commission documents. (2001). Official Journal of the European Union, L 145.

Rossi, L., \& Vinagre e Silva, P. (2017). Public access to documents in the EU. Oxford: Hart.

\section{About the Author}

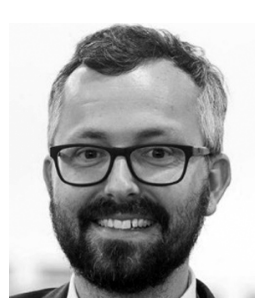

Maarten Hillebrandt is Postdoctoral Researcher at the Erik Castrén Institute, University of Helsinki, where he is involved in an Academy of Finland-funded research project on the transparency of EU decision making. Maarten specialises in EU institutional law, government transparency policy, and the politics of administration. Appertaining to various academic disciplines, his research has appeared in nationally and internationally recognised journals of law, political science, public administration, and sociology. 